\title{
Eating disorders: not such a slim speciality?
}

\author{
Anne Ward, Rosalind Ramsay and Janet Treasure
}

\begin{abstract}
"...the inferior health status of women can be regarded as a violation of international agreements." (Cook, 1994)
\end{abstract}

We believe that planners and providers of health care neglect the growing speciality of eating disorders. A report from the recent Cairo Health Conference, The Invisible Woman', indicates this might be expected as women's health generally is still globally undervalued (Editorial, 1994). Evidence of gender imbalance occurs widely in the management of both physical and mental illness. For example, in cardiovascular medicine, the higher mortality in women in the first month after a myocardial infarct has been attributed to undertreatment with beta-blockers (Wilkinson et al, 1994). In psychological medicine, primary care physicians are less likely to diagnose psychological problems in men, but once diagnosed, men are more likely to be referred for specialist help (Hopkins et al, 1969). As women move towards equality, we might expect our numbers to push us into a political ascendancy, and that men will use defensive manoeuvres to preserve the status quo. In psychiatry, this may be to deny the importance of women's illness. In a field such as eating disorders in which the majority of patients are women, there is scope for discrimination against the speciality as a whole.

The provision of services and training for psychiatrists in eating disorders is poor (Royal College of Psychiatrists Eating Disorders Working Group Report, 1992). Failure to develop services has occurred despite an exponential increase in hospital readmission rates for anorexia nervosa (Williams \& King, 1987; Nielsen, 1990), and now a 2\% prevalence of bulimia nervosa among young women (Bushnell, 1990; Kendler, 1991). In a sample of psychiatric residents in training in Canada, about $40 \%$ showed moderate to marked interest in working with eating disorders, but only $22 \%$ had received adequate teaching on the subject at medical school (Ghadirian \& Leichner, 1990). A recent survey of psychiatric tutors which asked about local services in the UK attracted replies such as "that's a symptom, not a disorder" and "we don't do that here" (personal communication to J. T.). Inadequate training and experience becomes more indefensible, as anorexia is now the third most chronic illness in teenage girls (Lucas et al, 1991).

One reason for the failure to develop services may be the lag in understanding of the range of problems the speciality now encompasses. The spectrum of presentation has broadened. perhaps reflecting the 'cult of thinness' in Westernised societies leading to neurotic disorders expressing themselves more frequently as anorexia or bulimia nervosa, without neurotic illnesses as a whole having necessarily become more frequent (Russell \& Treasure, 1989). Another reason for failure of appropriate recognition could be, paradoxically, the media attention given to the disorders which has tended to glamorise the illness, making it difficult to take seriously. Such lay interest is not new, and fasting women have historically been a source of fascination for the public (Vandereycken, 1993). Today, anorexia nervosa is often referred to in the media as the 'slimmer's disease', a misrepresentation of its psychopathology. Such concepts can fuel animosity rather than understanding of the illness among professionals. 'We are of course anxious to feed those who take insufficient food, but if frustrated our anxiety quickly turns to hostility at what seems to be an unnecessary, self-imposed disease' (Morgan, 1977).

Naomi Wolf suggests, perhaps with tongue in cheek, that the cult of thinness is part of a male plot to keep women weak and defenceless (1991). Women's bodies have always been subject to pressure to defy their anatomy, foot binding in China being a particularly barbaric example. Dieting is a multi-million pound industry, and any attempt to challenge its 
pervasive hold must face powerful business interests. This polemic may seem extreme, but there may be elements of truth in the idea, with women themselves contributing a subconscious fear of appearing aggressive or threatening. Another strand in the pursuit of thinness may be disidentification with the mother figure, whose role as carer and provider has been somewhat devalued. Equality is a complex and hard won concept.

There are a variety of treatments psychiatrists can use with these patients. For anorexia nervosa, they include different types of individual or family therapy in a variety of settings. In bulimia nervosa, where the research and development of interventions have proceeded more rapidly (Freeman, 1991), an even greater variety of approaches is possible. Psychiatrists have a particularly important role in the management of these patients, who need both medical and psychiatric care, and not infrequently a degree of medico-legal expertise. The psychiatrist must also be adept at facilitating a multidisciplinary approach with a group of patients known for their ability to cause splitting and denial in staff, mirroring features of the illness itself. It seems surprising that we pay so little attention to a psychiatric disorder carrying a significant mortality which may, however, respond to treatment. The economic burden of treatment is considerable, for example a Danish study has recently found that anorexia nervosa is second only to paranoid psychosis and schizophrenia in terms of treatment costs. As eating disorders continue to increase in frequency and diversity of presentation, training in their management will become more necessary and also of more general value to all psychiatrists.

In conclusion, the field of eating disorders in the 1990s is expanding, both as a speciality in itself and as a necessary part of general psychiatry. The developing process has not been allowed adequate serious recognition, either by the lay public, or within the profession. It is almost as if the characteristic anorexic process was occurring on a larger scale, with the threat of a mature female voice leading to denial and infantilisation. The adoption of a more enlightened approach to this predominantly women's speciality will allow it to realise a fuller potential, with benefits to psychiatry as a whole. Eating disorders is no longer such a slim speciality.

\section{References}

Bushnell, J. A., Wels, J. E., HoRnBlow, A. R., et al (1990) Prevalence of three bulimia syndromes in the general population. Psychological Medicine, 20, 671-680.

CoOK, R. J. (1994) Women's Health and Human Rights. Geneva: World Health Organization.

EDITORIAL (1994) The Invisible Woman. Lancet, $\mathbf{3 4 4 .}$ $697-698$.

Freeman, C. P. (1991) International symposium on eating disorders (editorial). Joumal of Psychosomatic Research. 35(suppl. 1), 1.

Ghadirian, A. M. \& Leichner, P. (1990) Psychiatric residents' educational experiences and attitudes towards eating disorders. Canadian Journal of Psychiatry. 35, 254-256.

HOPKINS, P. \& COOPER, B. (1969) Psychiatric referral from a general practice. British Journal of Psychiatry, 116. 1163-1174.

Kendler, K. S., MacClean, C., Neale, M., et al (1991) The genetic epidemiology of bulimia nervosa. American Journal of Psychiatry. 148, 1627-1637.

LUCAS, A. R., BEARD, C. M., O'FALLON, W. M., et al (1991) 50 year trends in the incidence of anorexia nervosa in Rochester, Minn.: a population-based study. American Journal of Psychiatry. 148, 917-922.

MORGaN, H. G. (1977) Fasting girls and our attitudes to them. Brttish Medical Journal. 2. 1652-1655.

NiELSEN, S. (1990) The epidemiology of anorexda nervosa in Denmark from 1973 to 1987: a nationwide register study of psychiatric admission. Acta Psychiatrica Scandanavica, 81, 507-514.

RoYal College OF PSYChIATRISTs (1992) Eating Disorders. Councll Report CR14. London: Royal College of Psychiatrists.

Russeu, G. F. M. \& TREAsure, J. (1989) The modern history of anorexia nervosa: an interpretation of why the illness has changed. In The Psychobiology of Human Eating Disorders: Preclinical and Clinical Perspectives (eds L. A. Schneider, S. J. Cooper \& K. A. Halmi). Annals of the New Academy of Sciences, 575, 13-30.

VANDEREYCKEN, W. (1993) Naughty girls and angry doctors: eating disorder patients and their therapists. International Review of Psychiatry, 5, 13-17.

WILxINSON, P., LAJl, K., RANUADAYALAN, K., et al (1994) Acute myocardial infarction in women: survival analysis in first six months. British Medical Journal, 309, 566-569.

WIuLAMS, P. \& KING, M. (1987) The 'epidemic' of anorexia nervosa: another medical myth? Lancet, 1, 205-207.

Wolf, N. (1991) The Beauty Myth: How Images of Beauty are Used against Women. New York: Morrow.

*Anne Ward, Honorary Senior Registrar, Eating Disorders Unit, Rosalind Ramsey, Senior Registrar; and Janet Treasure, Consultant, Institute of Psychiatry, De Crespigny Park, Denmark Hill, London SE5 8AF 